\title{
An in vitro study on the efficacy of removing calcium hydroxide from curved root canal systems in root canal therapy
}

\author{
Ying Wang ${ }^{1,2, \star}$ Li-Yang Guo ${ }^{1, \star}$, Hong-Zhi Fang ${ }^{3}$, Wen-Ling Zou ${ }^{1}$, Ying-Ming Yang ${ }^{4}$, Yuan Gao ${ }^{1}$, Hui Yang ${ }^{5}$ \\ and $\mathrm{Tao} \mathrm{Hu}^{1,4}$
}

To compare the efficacy of various irrigants (citric acid, ethylenediaminetetraacetic acid (EDTA) and $\mathrm{NaOCl}$ ) and techniques in removing $\mathrm{Ca}(\mathrm{OH})_{2}$ in two types of curved root canal systems, simulated root canals with specific curvatures were used to investigate the effects of different irrigants and instruments on $\mathrm{Ca}(\mathrm{OH})_{2}$ removal. The optimal methods were verified on extracted human teeth. Simulated root canals were assigned to one of two groups based on the irrigation solution: $10 \%$ citric acid or $2.5 \% \mathrm{NaOCl}$. Each group was divided into four subgroups according to the technique used to remove $\mathrm{Ca}(\mathrm{OH})_{2}$. The percentage of $\mathrm{Ca}(\mathrm{OH})_{2}$ removal in different sections of root canals was calculated. On the basis of the results obtained for the simulated canals, $10 \%$ citric acid and $17 \%$ EDTA were applied to remove $\mathrm{Ca}(\mathrm{OH})_{2}$ from the extracted human teeth with curved root canal systems. The teeth were scanned by micro computed tomography to calculate the percentage of $\mathrm{Ca}(\mathrm{OH})_{2}$ removal in the canals. In simulated root canals, we found that $10 \%$ citric acid removed more $\mathrm{Ca}(\mathrm{OH})_{2}$ than $2.5 \% \mathrm{NaOCl}$ in the $0-1 \mathrm{~mm}$ group from the apex level $(P<0.05)$. Ultrasonic and EndoActivator activation significantly removed more $\mathrm{Ca}(\mathrm{OH})_{2}$ than a size $30 \mathrm{~K}$ file in the apical third $(P<0.05)$. However, there were no significant differences in any sections of the canals for $10 \%$ citric acid or $17 \%$ EDTA in removing $\mathrm{Ca}(\mathrm{OH})_{2}$ in extracted human teeth. We concluded that it was effective to remove residual $\mathrm{Ca}(\mathrm{OH})_{2}$ using the decalcifying solution with EndoActivator or Passive Ultrasonic Irrigation in a curved root canal system. A protocol for $\mathrm{Ca}(\mathrm{OH})_{2}$ removal was provided based on the conclusions of this study and the methods recommended in previous studies. International Journal of Oral Science (2017) 9, 110-116; doi:10.1038/ijos.2017.14; published online 23 June 2017

Keywords: calcium hydroxide; curved root canal system; irrigation; removal

\section{INTRODUCTION}

Overwhelming evidence indicates that microorganisms have a fundamental role in the pathogenesis of periradicular diseases. ${ }^{1}$ To eliminate the remaining microbes after root canal preparation and to prevent an interappointment reinfection of the root canal system, intracanal medications are recommended. ${ }^{2}$ Calcium hydroxide $\left[\mathrm{Ca}(\mathrm{OH})_{2}\right]$ has been widely used as an intracanal medication owing to its good antibacterial properties and biocompatibility. ${ }^{2}$ However, some studies have indicated that $\mathrm{Ca}(\mathrm{OH})_{2}$ inactivates endotoxin $^{3}$ and impedes the increase in cytokine chemical inflammatory mediators ${ }^{4-5}$ to inhibit periapical inflammation after a root canal cleaning procedure.
The antibacterial effect of $\mathrm{Ca}(\mathrm{OH})_{2}$ is most effective after direct contact with microorganisms. ${ }^{2,6}$ Therefore, it is important to obtain a compact and homogenous filling of $\mathrm{Ca}(\mathrm{OH})_{2}$ in the entire root canal system. ${ }^{6}$ Before obturation, $\mathrm{Ca}(\mathrm{OH})_{2}$ should be completely removed from the root canal system to avoid any possible negative influence on treatment. Residual $\mathrm{Ca}(\mathrm{OH})_{2}$ might lead to apical leakage ${ }^{7}$ and reduced sealer adaptation, ${ }^{8}$ and might interact with zinc oxide eugenol $^{9}$ and decrease the dentin bond strength. ${ }^{10}$ Therefore, any Ca $(\mathrm{OH})_{2}$ that is placed in the root canal system as an intracanal medication must be completely removed before root canal obturation.

The most frequently described method for removing $\mathrm{Ca}(\mathrm{OH})_{2}$ from the root canal is the instrumentation of the root canal with the master

${ }^{1}$ State Key Laboratory of Oral Disease, National Clinical Research Center for Oral Diseases, West China Hospital of Stomatology, Sichuan University, Chengdu, China; ${ }^{2}$ Department of Endodontics, The Affiliated Stomatology Hospital, School of Medicine, Zhejiang University, Hangzhou, China; ${ }^{3}$ Department of Stomatology, The Third People's Hospital of Chengdu, Chengdu, China; ${ }^{4}$ State Key Laboratory of Oral Disease, National Clinical Research Center for Oral Diseases, Department of Preventive Dentistry, West China Hospital of Stomatology, Sichuan University, Chengdu, China and ${ }^{5}$ State Key Laboratory of Oral Disease, National Clinical Research Center for Oral Diseases, Department of General Dentistry, West China Hospital of Stomatology, Sichuan University, Chengdu, China

*These authors contributed equally to this work.

Correspondence: Dr H Yang, State Key Laboratory of Oral Diseases, National Clinical Research Center for Oral Diseases, Department of General Dentistry, West China Hospital of Stomatology, Sichuan University, No. 14, 3rd Section, Renmin South Road, Chengdu 610041, China

E-mail: yanghui09@scu.edu.cn

Professor T Hu, State Key Laboratory of Oral Diseases, National Clinical Research Center for Oral Diseases, Department of Preventive Dentistry, West China Hospital of Stomatology, Sichuan University, No. 14, 3rd Section, Renmin South Road, Chengdu 610041, China

E-mail: hutao@scu.edu.cn

Accepted 28 March 2017 
apical file in combination with copious irrigation. ${ }^{2,11}$ Previous studies have investigated the efficacy of $\mathrm{Ca}(\mathrm{OH})_{2}$ removal with different irrigants, equipment and techniques. Rödig et al. ${ }^{12}$ indicated that decalcifying solution, such as citric acid and ethylenediaminetetraacetic acid (EDTA), was significantly more effective than sodium hypochlorite and water. Decalcifying solutions in endodontics comprise chelators and acid. ${ }^{13}$ Rotary instruments, the self-adjusting file system and high-efficiency irrigation systems, such as passive ultrasonic irrigation and the EndoVac system, were significantly more effective than conventional syringes. ${ }^{14-16}$ However, none of these methods completely removed the $\mathrm{Ca}(\mathrm{OH})_{2}$ intracanal medication. Although more techniques have been proposed to remove $\mathrm{Ca}(\mathrm{OH})_{2}$, an effective and systematic $\mathrm{Ca}(\mathrm{OH})_{2}$ removal strategy is not available.

Most studies of $\mathrm{Ca}(\mathrm{OH})_{2}$ removal have used extracted human teeth with straight root canals. ${ }^{12}$ Some researchers have established artificial standardized grooves in root canal apices to study $\mathrm{Ca}(\mathrm{OH})_{2}$ removal for irregular parts of the root canal system. ${ }^{14-16}$ To evaluate the quantity of $\mathrm{Ca}(\mathrm{OH})_{2}$ remaining after removal with various techniques in curved root canal systems, extracted human teeth with curved root canals with a certain range of curvature were selected in previous studies. ${ }^{17}$ Because canal anatomy is one of the main confounding factors affecting the experimental results, ${ }^{18}$ especially in complicated root canal systems, the experimental groups should be anatomically comparable to maintain a consistent baseline for the validity of experimental results. It is difficult for extracted human teeth to meet this condition as experimental specimens because of their heterogeneity. To research the shaping ability of rotary instruments in severely curved canals, Schäfer attempted to ensure standardization of the experimental groups by balancing them with respect to the root canal angle and the radius of canal curvature. The homogeneity of the groups was examined using statistical methods. ${ }^{19}$ Simulated root canal models were proposed to create an undifferentiated experimental group in studies regarding a certain curvature. Some researchers used simulated root canals to mimic the actual curved canal system. ${ }^{20}$ This in vitro model ensures standardization, provides a consistent baseline for each experimental group and avoids the confounding factors from root canal anatomy, such as the isthmus, length, curvature and radius. The curved root canal models used in previous studies offer a new choice to establish a more rational model for $\mathrm{Ca}(\mathrm{OH})_{2}$ removal research in curved root canal systems.

The objective of the present study was to compare the efficacy of different irrigants (citric acid, EDTA and $\mathrm{NaOCl}$ ) and techniques (rotary instrumentation, sonic and passive ultrasonic irrigation) in removing $\mathrm{Ca}(\mathrm{OH})_{2}$ in two curved root canal models: simulated root canals and extracted human teeth.

\section{MATERIALS AND METHODS}

\section{Sample preparation for simulated curved root canals}

This experiment consisted of 20 simulated curved root canals (Endo Training Block; DentsplyMaillefer, Ballaigues, Switzerland) that were $16.5 \mathrm{~mm}$ long. The degree of curvature was $45.2^{\circ}$, and the radius of canal curvature was $6.1 \mathrm{~mm}$, according to Schneider's method. ${ }^{21}$ The canals were prepared to F3 (apical size 30 with a 0.09 taper) by the same operator using a ProTaperNiTi Rotary System (DentsplyMaillefer, Ballaigues, Switzerland) according to the manufacturer's instructions. ${ }^{22} 5 \mathrm{~mL}$ of $2.5 \% \mathrm{NaOCl}$ was used after each instrument, and $5 \mathrm{~mL}$ of distilled water was used as the final rinse. The simulated root canals were dried with paper points. The apical foramen was then filled with wax from the outside. ${ }^{22}$ Canals were filled with $\mathrm{Ca}(\mathrm{OH})_{2}$ paste (UltracalXSOptident, International) using a 30-gauge NaviTip (Ultradent products Inc., South
Jordan, UT, USA) starting from the apical aspect with the needle slowly advancing coronally until the paste was visualized at the canal orifice. ${ }^{6}$ The access cavities were sealed with a cotton pellet and temporary filling material (GC corporation, Tokyo, Japan). The root canals were stored at $37^{\circ} \mathrm{C}$ and $100 \%$ relative humidity for 7 days.

Different irrigants and different instruments in calcium hydroxide removal in simulated curved root canals

Before the experiment, the temporary filling material was removed, and the $\mathrm{Ca}(\mathrm{OH})_{2}$ in the simulated canals was loosened using a $15 \mathrm{~K}$ file. There were two experimental groups based on the irrigation solutions used to remove $\mathrm{Ca}(\mathrm{OH})_{2}$. In group 1 , the canals were irrigated with $10 \%$ citric acid. In group 2 , the canals were irrigated with $2.5 \% \mathrm{NaOCl}$. All canals were irrigated following a standardized protocol. The operating cycle included $5 \mathrm{~mL}$ of irrigant and different techniques, and the final rinse was performed after two operating cycles. A 30-gauge NaviTip (Ultradent) needle was used at a length that was $2 \mathrm{~mm}$ shorter than working length, ${ }^{17}$ and the pressure applied to the plunger was standardized to $19.6 \mathrm{~N}$ using the device designed for this experiment (Figure 1a and $1 \mathrm{~b}$ ). Each group was divided into four subgroups according to the technique used to remove $\mathrm{Ca}(\mathrm{OH})_{2}$. In subgroup $1(n=10)$, canals were filed manually with a $30 \mathrm{~K}$ file in a circumferential filing action at working length for 10 s. In subgroup 2 $(n=10)$, canals were filed with a size F3 instrument with a rotatinglifting action at working length for $10 \mathrm{~s}$. In subgroup $3(n=10)$, ultrasonic activation was delivered for $30 \mathrm{~s}$ with a stainless steel ultrasonic file 15/0.2 (Irri-Safe Satelec; Acteon Group, Merignac, France) mounted on a Suprasson P5 Booster ultrasonic unit (Satelec, Acteon Group, Merignac, France) with the power setting at $5 .{ }^{17}$ In subgroup $4(n=10)$, sonic activation was delivered for $30 \mathrm{~s}$ between each irrigant using the EndoActivator (Advanced Endodontics, Santa Barbara, CA, USA) set at 10000 cycles per minute with a 35/0.04 tip according to the manufacturer's instructions. The final rinse was performed with $3 \mathrm{~mL}$ of distilled water after two cycles of irrigation. The transparent blocks were covered with adhesive tape during the instrumentation phase. After ensuring that the residues in each root canal were adequately cleaned, the simulated root canals were reused. Each canal was reused three times.

\section{Efficacy of calcium hydroxide removal in simulated curved root} canals

The $\mathrm{Ca}(\mathrm{OH})_{2}$ removal process was recorded by a camcorder (ScopeTek DCM 310; ScopeTek, Hang Zhou, China) operated in macro mode (Figure 1a). A ring light was fixed on the camcorder to ensure the images were obtained with a standard light source. After the removal of $\mathrm{Ca}(\mathrm{OH})_{2}$, the images were obtained using a camcorder. The images were analysed using Image-Pro Plus 6.0 (Media Cybernetics, Rockville, MD, USA) on a laptop computer (HP, Palo Alto, CA, USA) with a $1366 \times 768$ screen pixel resolution to quantify the proportion of pixels for residual $\mathrm{Ca}(\mathrm{OH})_{2}$ compared with the total area of the root canal wall. The software identified the residual area according to the different grey level between the residual area and the clear area. Then, the percentage of the $\mathrm{Ca}(\mathrm{OH})_{2}$ removal area was calculated. The apical third was re-divided into three portions according to their distance from the apex: $0-1 \mathrm{~mm}, 1-3 \mathrm{~mm}$ and 3$5 \mathrm{~mm}$. The percentage of $\mathrm{Ca}(\mathrm{OH})_{2}$ removal in the apical, middle and coronary thirds together with the three portions in the apical part of the root canal was calculated. Two endodontists independently evaluated the images. When there were disagreements about the image, another endodontist was asked to perform a third evaluation to 


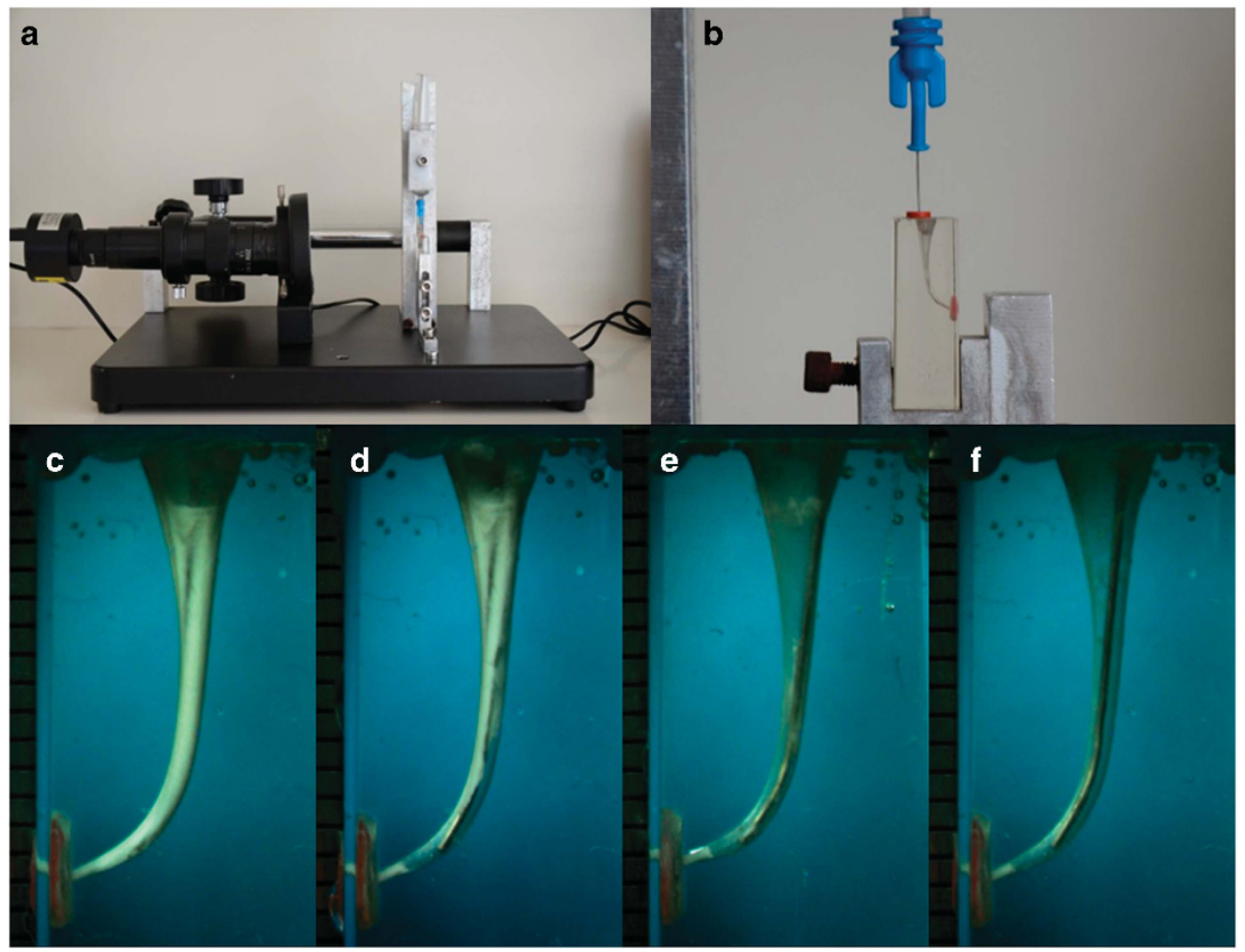

Figure 1 The experimental apparatus and operational process of $\mathrm{Ca}(\mathrm{OH})_{2}$ removal. (a) The experimental set-up, including a camcorder and fixing device. (b) Simulated curved root canals and syringe needle. (c-f) Images after $0 \mathrm{~mL}, 5 \mathrm{~mL}, 10 \mathrm{~mL}$ and $15 \mathrm{~mL}$ of irrigation. Syringe needle inserted $2 \mathrm{~mm}$ from the apex. Between each 5-mL irrigation, different instruments were applied to remove $\mathrm{Ca}(\mathrm{OH})_{2}$.

Table 1 Characteristics of curved root canals

\begin{tabular}{|c|c|c|c|c|c|c|}
\hline \multirow[t]{2}{*}{ Group } & \multicolumn{3}{|c|}{ Curvature/ ${ }^{\circ}$} & \multicolumn{3}{|c|}{ Radius/mm } \\
\hline & Mean \pm s.d. & Maximum & Minimum & Mean \pm s.d. & Maximum & Minimum \\
\hline Group $1(n=12)$ & $34.61 \pm 7.97$ & 47.7 & 25.2 & $7.53 \pm 2.27$ & 10.1 & 3.5 \\
\hline Group $2(n=12)$ & $35.26 \pm 7.30$ & 46.2 & 28.0 & $7.66 \pm 2.01$ & 9.5 & 4.9 \\
\hline$P$-value & 0.465 & & & 0.901 & & \\
\hline
\end{tabular}

s.d., standard deviations.

achieve a final consensus. The presence of $\mathrm{Ca}(\mathrm{OH})_{2}$ in the apical third was scored (absence was scored as "0", and presence was scored as "1") according to the three portions determined in the apical part.

\section{Sample preparation for the extracted teeth}

A total of 24 recently extracted human teeth with at least one curved root and curved root canal were selected. These teeth were obtained from the Oral Surgery Department of West China Hospital of Stomatology, and this study was approved by the Ethics Committee of West China Hospital of Stomatology. The degree of curvature was measured according to Schneider's technique with $\mathrm{CBCT},{ }^{23}$ and the radius of canal curvature was calculated. Teeth with a radius of curvature ranging from 3.5 to $10.1 \mathrm{~mm}$ and a degree of curvature ranging from $25.2^{\circ}$ to $47.7^{\circ}$ were included (Table 1). Two similar groups were established with respect to the degree and the radius of curvature. The homogeneity of the two groups was assessed using the paired $t$-test (Table 1 ).

The working length was established as $1 \mathrm{~mm}$ less than the length of the initial instrument (size 10) at the apical foramen. Root canals were prepared to F3. The preparation and $\mathrm{Ca}(\mathrm{OH})_{2}$ application procedures were the same as mentioned above. Teeth were stored at $37^{\circ} \mathrm{C}$ and $100 \%$ relative humidity for 7 days.

Different irrigants and different instruments in calcium hydroxide removal in the curved root canals of extracted teeth

The results from the simulated curved root canals indicated that decalcifying solution was more effective in removing $\mathrm{Ca}(\mathrm{OH})_{2}$. To verify the efficacy of commonly used decalcifying solution in removing $\mathrm{Ca}(\mathrm{OH})_{2}, 10 \%$ citric acid (group 1) and 17\% EDTA (group 2) were applied in the two groups. EndoActivator was used for $30 \mathrm{~s}$ between each $5-\mathrm{mL}$ irrigation. A final rinse was performed with $2 \mathrm{~mL}$ of irrigant and $3 \mathrm{~mL}$ of distilled water after two cycles of irrigation. The total activation time was $60 \mathrm{~s}$. Root canals were dried with paper points after the $\mathrm{Ca}(\mathrm{OH})_{2}$ removal procedure. Other operations followed the procedure of the simulated root canals mentioned above. 
Micro-computed tomography scanning

The teeth were scanned by micro-computed tomography (micro-CT; $\mu \mathrm{CT}$ 5.0, SCANCO Medical AG, Brüttisellen, Switzerland) with an isotropic voxel size of $38 \mu \mathrm{m}$ at the following time points: after root canal instrumentation, after $\mathrm{Ca}(\mathrm{OH})_{2}$ application and after $\mathrm{Ca}(\mathrm{OH})_{2}$ removal. All cross-sections obtained were roughly perpendicular to the long axis of the root. The image serials were analysed using ImageJ. The volume of residual $\mathrm{Ca}(\mathrm{OH})_{2}$ was measured. Then, the percentage of $\mathrm{Ca}(\mathrm{OH})_{2}$ removal in the canals was calculated according to the method described in Ma's research. ${ }^{24}$

Statistical analysis

Data were presented as the mean \pm standard deviations (s.d.). Differences between the groups were determined using an unpaired Student's $t$-test. ANOVA with post hoc Tukey's test was used for statistical analysis at a 95\% confidence level. Statistical significance was established at $P$-values less than 0.05 .

\section{RESULTS}

The percentages of $\mathrm{Ca}(\mathrm{OH})_{2}$ removal in simulated root canals are shown in Table 2 and Table 3 and Figure 2. The scores of the residual $\mathrm{Ca}(\mathrm{OH})_{2}$ are shown in Figure 3.

In each group, $\mathrm{Ca}(\mathrm{OH})_{2}$ was almost completely removed in the middle and coronal thirds. For the apical third, ultrasonic irrigation and EndoActivator removed more $\mathrm{Ca}(\mathrm{OH})_{2}$ than the size $30 \mathrm{~K}$ file in the $10 \%$ citric acid group, but the difference was not significant $(P>0.05)$. In the $2.5 \% \mathrm{NaOCl}$ group, the $30 \mathrm{~K}$ file removed less $\mathrm{Ca}$ $(\mathrm{OH})_{2}$ than ultrasonic irrigation and the EndoActivator $(P<0.05)$. There were no significant differences between the groups in the apical third $(P>0.05)$.

Table 2 Mean percentage of $\mathrm{Ca}(\mathrm{OH})_{2}$ removal with different techniques from simulated root canals in the coronal, middle and apical sections

\begin{tabular}{|c|c|c|c|c|c|c|c|c|}
\hline \multirow[t]{2}{*}{ Group } & \multicolumn{4}{|c|}{ Group 1 ( $10 \%$ citric acid, $n=10)$} & \multicolumn{4}{|c|}{ Group $2(2.5 \% \mathrm{NaOCl}, n=10)$} \\
\hline & Whole canal & Cervical $1 / 3$ & Middle $1 / 3$ & Apical 1/3 & Whole canal & Cervical $1 / 3$ & Middle $1 / 3$ & Apical $1 / 3$ \\
\hline SG2 & $99.67 \% \pm 0.29 \%$ & $100 \% \pm 0 \%$ & $100 \% \pm 0 \%$ & $98.10 \% \pm 1.68 \%$ & $99.37 \% \pm 0.41 \%$ & $100 \% \pm 0 \%$ & $100 \% \pm 0 \%$ & $96.43 \% \pm 2.33 \%$ \\
\hline SG3 & $99.79 \% \pm 0.23 \%$ & $100 \% \pm 0 \%$ & $100 \% \pm 0 \%$ & $98.82 \% \pm 1.34 \%$ & $99.69 \% \pm 0.28 \%$ & $100 \% \pm 0 \%$ & $100 \% \pm 0 \%$ & $98.25 \% \pm 1.61 \%$ \\
\hline SG4 & $99.83 \% \pm 0.22 \%$ & $100 \% \pm 0 \%$ & $100 \% \pm 0 \%$ & $99.02 \% \pm 1.26 \%$ & $99.72 \% \pm 0.26 \%$ & $100 \% \pm 0 \%$ & $100 \% \pm 0 \%$ & $98.43 \% \pm 1.50 \%$ \\
\hline
\end{tabular}

SG1, $30 \mathrm{~K}$ file; SG2, F3 instrument; SG3, passive ultrasonic irrigation; SG4, EndoActivator. Values represent mean \pm standard deviations.

Table 3 Mean percentage of $\mathrm{Ca}(\mathrm{OH})_{2}$ removal with different techniques from simulated root canals in three sections in the apical $1 / 3$

\begin{tabular}{|c|c|c|c|c|c|c|}
\hline \multirow[t]{2}{*}{ Group } & \multicolumn{3}{|c|}{$10 \%$ citric acid $(n=10)$} & \multicolumn{3}{|c|}{$2.5 \% \mathrm{NaOCl}(n=10)$} \\
\hline & 0-1 mm & $1-3 \mathrm{~mm}$ & $3-5 \mathrm{~mm}$ & $0-1 \mathrm{~mm}$ & $1-3 \mathrm{~mm}$ & $3-5 \mathrm{~mm}$ \\
\hline SG1 & $87.81 \% \pm 11.46 \%$ & $96.48 \% \pm 4.90 \%$ & $99.42 \% \pm 1.28 \%$ & $73.86 \% \pm 12.84 \%$ & $95.30 \% \pm 5.58 \%$ & $99.21 \% \pm 1.36 \%$ \\
\hline SG2 & $87.85 \% \pm 9.82 \%$ & $99.29 \% \pm 1.50 \%$ & $100 \% \pm 0 \%$ & $79.37 \% \pm 10.30 \%$ & $99.21 \% \pm 1.41 \%$ & $98.96 \% \pm 3.28 \%$ \\
\hline SG3 & $91.22 \% \pm 9.95 \%$ & $100 \% \pm 0 \%$ & $100 \% \pm 0 \%$ & $87.01 \% \pm 11.95 \%$ & $100 \% \pm 0 \%$ & $100 \% \pm 0 \%$ \\
\hline SG4 & $92.73 \% \pm 9.37 \%$ & $100 \% \pm 0 \%$ & $100 \% \pm 0 \%$ & $82.15 \% \pm 12.75 \%$ & $100 \% \pm 0 \%$ & $100 \% \pm 0 \%$ \\
\hline
\end{tabular}

SG1, $30 \mathrm{~K}$ file; SG2, F3 instrument; SG3, passive ultrasonic irrigation; SG4, EndoActivator. Values represent mean \pm standard deviations.

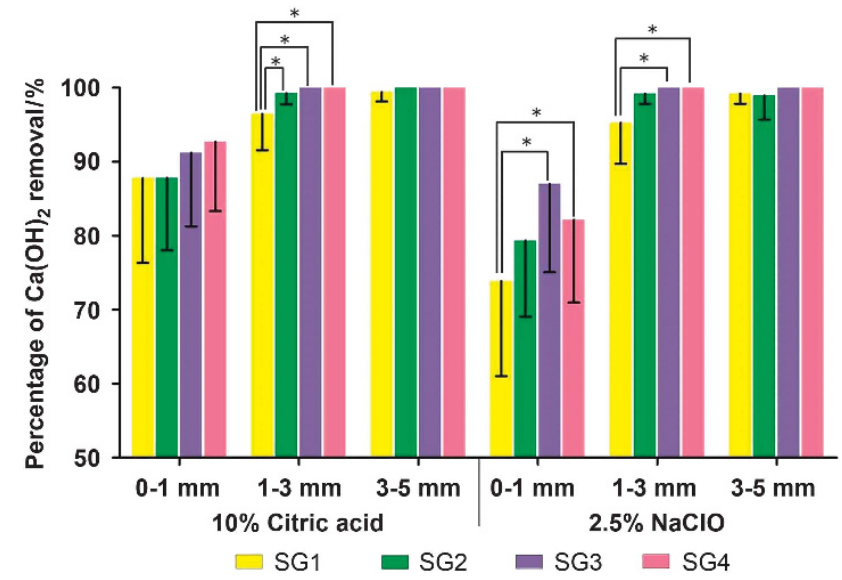

Figure 2 The percentage of $\mathrm{Ca}(\mathrm{OH})_{2}$ removal in each region of the apical third with $10 \%$ citric acid or $2.5 \% \mathrm{NaOCl}$ combined with different instruments ( $\left.{ }^{*} P<0.05\right)$.

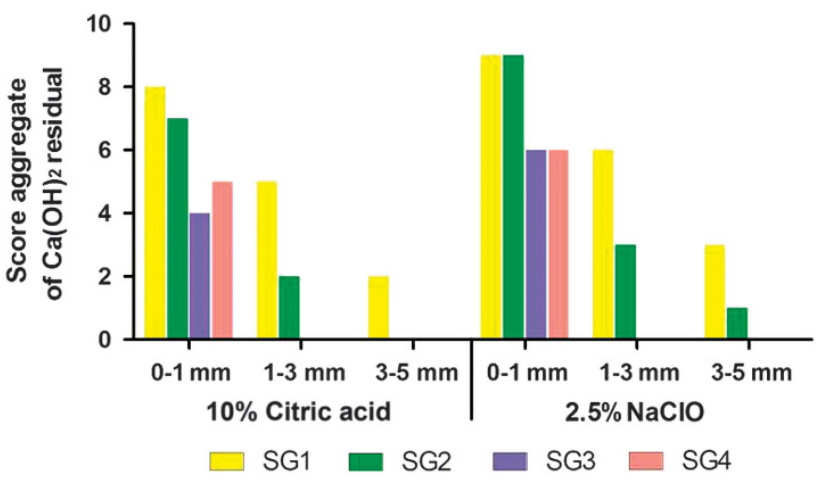

Figure 3 Score distribution for the three regions in the apical third with $10 \%$ citric acid and $2.5 \% \mathrm{NaOCl}$. 
In the apical $1-3 \mathrm{~mm}$ region, $10 \%$ citric acid with a $30 \mathrm{~K}$ file $(96.48 \% \pm 4.90 \%)$ was not as effective as rotary instrumentation $(99.29 \% \pm 1.50 \%)$, ultrasonic $(100 \% \pm 0 \%)$ or EndoActivator activation $(100 \% \pm 0 \% ; P<0.05)$. However, there were no significant differences in other root canal regions $(P>0.05)$. For the $2.5 \% \mathrm{NaOCl}$

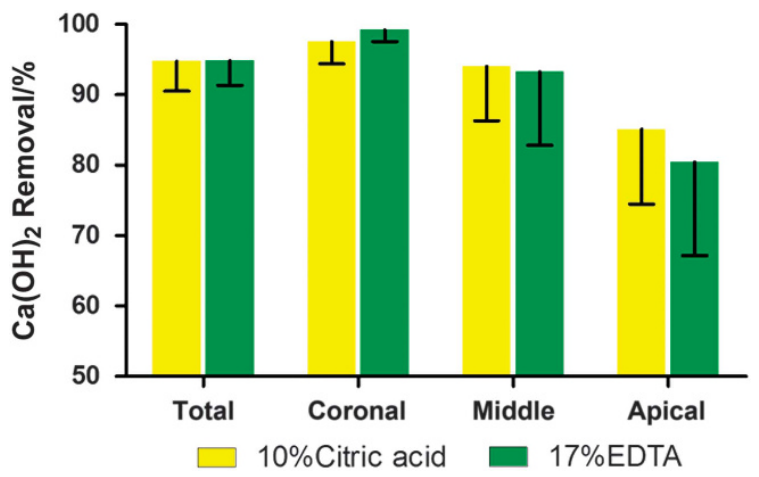

Figure 4 The percentage of $\mathrm{Ca}(\mathrm{OH})_{2}$ removal for the entire canal and each third of the root canal system.
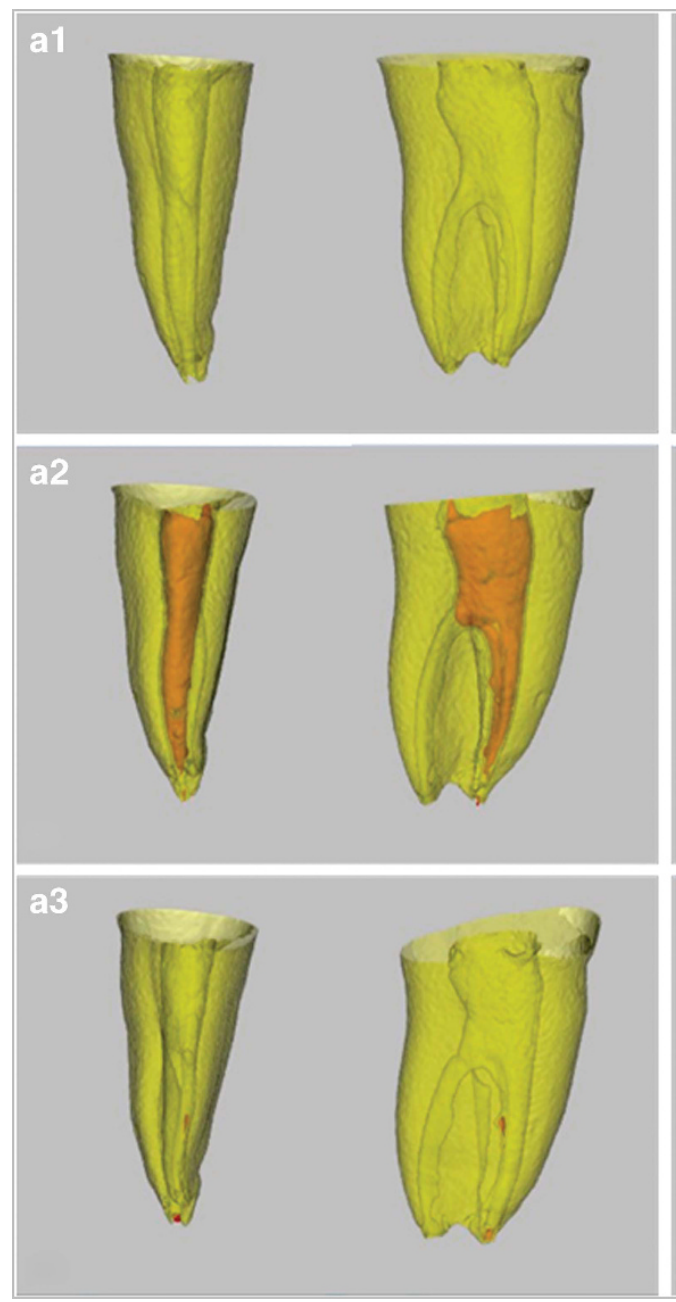

group, ultrasonic and EndoActivator activation significantly removed more $\mathrm{Ca}(\mathrm{OH})_{2}$ than the size $30 \mathrm{~K}$ file in the apical one-third and the apical $0-1 \mathrm{~mm}$ and apical $1-3 \mathrm{~mm}$ groups $(P<0.05)$. For the two groups, $\mathrm{Ca}(\mathrm{OH})_{2}$ was completely removed at the $1-5 \mathrm{~mm}$ level using ultrasonic irrigation and the EndoActivator. At the apical $0-1 \mathrm{~mm}$ level, the $10 \%$ citric acid group removed significantly more $\mathrm{Ca}(\mathrm{OH})_{2}$ than $2.5 \% \mathrm{NaOCl}$ when using a $30 \mathrm{~K}$ file $(P<0.05)$. No significant differences were noted for other subgroups at the $0-1 \mathrm{~mm}$ level $(P>0.05)$, but the $10 \%$ citric acid group removed more $\mathrm{Ca}(\mathrm{OH})_{2}$. On the basis of the results of the scores in different segments, we found that residual $\mathrm{Ca}(\mathrm{OH})_{2}$ frequently remained in the apical $0-1 \mathrm{~mm}$ segment. Ultrasonic and EndoActivator activation could improve the $\mathrm{Ca}(\mathrm{OH})_{2}$ removal in the apical $1-3 \mathrm{~mm}$ and $3-5 \mathrm{~mm}$ sections.

In human extracted teeth, the effect of two decalcifying solutions in removing $\mathrm{Ca}(\mathrm{OH})_{2}$ is illustrated in Figure 4. There were no significant differences in any sections of the canal irrigated either with $10 \%$ citric acid or with $17 \%$ EDTA in removing $\mathrm{Ca}(\mathrm{OH})_{2}(P>0.05)$. For $33 \%$ of the samples, $\mathrm{Ca}(\mathrm{OH})_{2}$ was completely removed by $10 \%$ citric acid. Residual $\mathrm{Ca}(\mathrm{OH})_{2}$ was found in the apical one-third, isthmus and irregular parts (Figure 5).
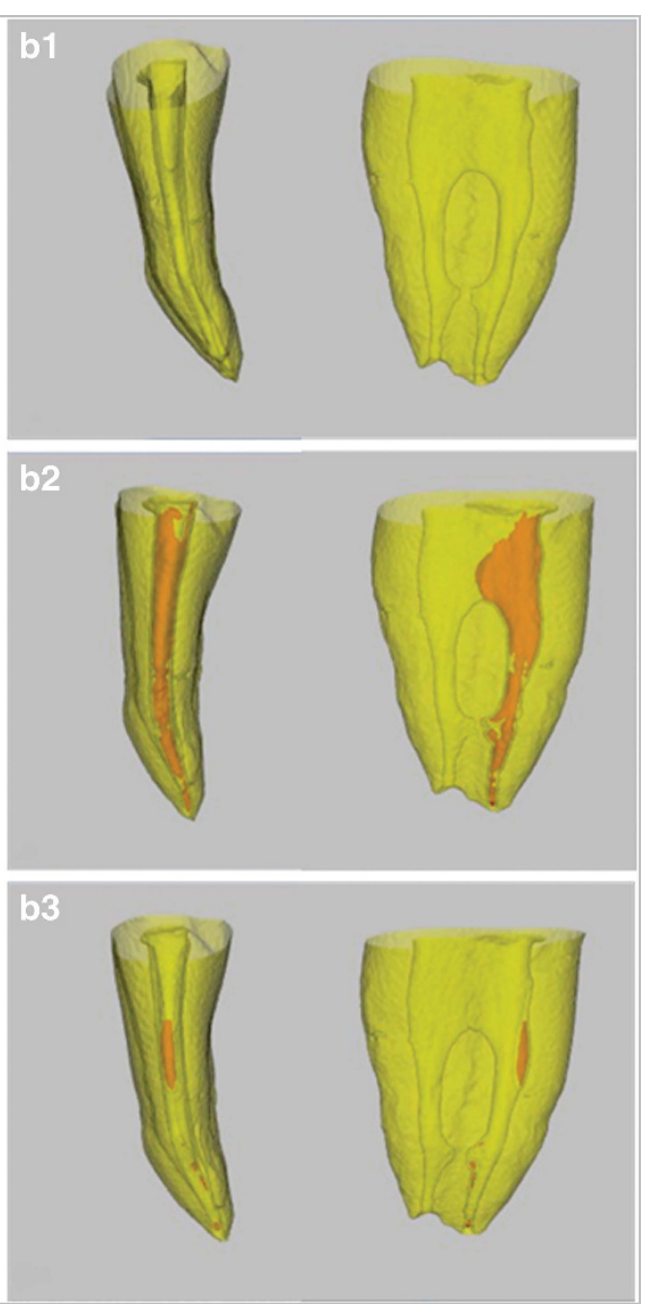

Figure 5 Micro-CT reconstructed images of extracted teeth. (a1-a3) Reconstructed images after root canal preparation, $\mathrm{Ca}(\mathrm{OH})_{2}$ medication and removal with $10 \%$ citric acid. (b1-b3) Reconstructed images after root canal preparation, $\mathrm{Ca}(\mathrm{OH})_{2}$ medication and removal with $17 \%$ EDTA. EDTA, ethylenediaminetetraacetic acid; micro-CT, micro-computed tomography. 


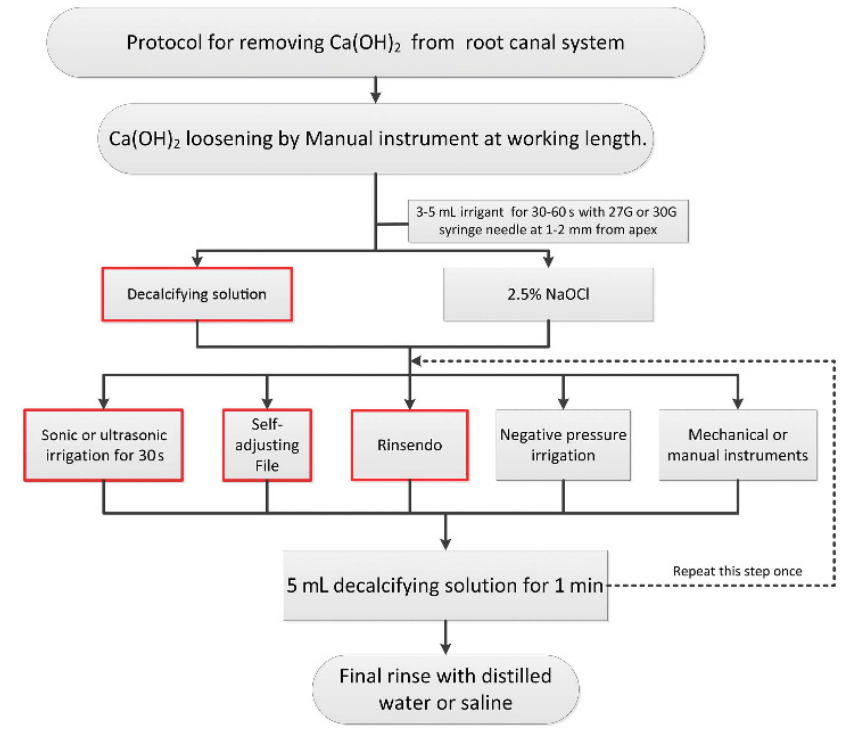

Figure 6 Recommended protocol for $\mathrm{Ca}(\mathrm{OH})_{2}$ removal (the red box indicates the preferred method).

\section{DISCUSSION}

This study investigated the effect of decalcifying solution and $\mathrm{NaOCl}$ on the removal of $\mathrm{Ca}(\mathrm{OH})_{2}$ in simulated curved root canals with different instruments. $\mathrm{Ca}(\mathrm{OH})_{2}$ could not be completely removed in all groups. However, decalcifying solution combined with sonic or ultrasonic agitation was the most effective method for removing $\mathrm{Ca}$ $(\mathrm{OH})_{2}$ in curved root canal systems. Sonic or ultrasonic irrigation enhanced the agitation and shearing stress of irrigants in the root canal wall, which was effective in removing debris in root canals. ${ }^{16,25}$ In a previous study, the use of citric acid as a decalcifying solution was more effective than $\mathrm{NaOCl}$ in $\mathrm{Ca}(\mathrm{OH})_{2}$ removal, ${ }^{12}$ and similar results were found in the present study. This finding might be explained by the fact that citric acid and $\mathrm{Ca}(\mathrm{OH})_{2}$ underwent a neutralization reaction. In addition, citric acid is a good chelating agent for removing the smear layer. However, $\mathrm{NaOCl}$ had a limited ability to dissolve inorganic substances, such as calcium. ${ }^{17,26}$

Residual $\mathrm{Ca}(\mathrm{OH})_{2}$ mainly remained in the apical part of the curved root canal. Residual $\mathrm{Ca}(\mathrm{OH})_{2}$ was frequently located at the $0-1 \mathrm{~mm}$ region from the apex, followed by a $1-3 \mathrm{~mm}$ region from the apex. The result was similar to previous studies in which more $\mathrm{Ca}(\mathrm{OH})_{2}$ remained in the apical one-third. ${ }^{15,24}$ Investigations that used passive ultrasonic irrigation and a master apical file to remove $\mathrm{Ca}(\mathrm{OH})_{2}$ found that there were no significant differences in the apical one-third. ${ }^{15}$ In this study, significant differences appeared between the $30 \mathrm{~K}$ file and sonic and ultrasonic irrigation groups when using $2.5 \% \mathrm{NaOCl}$. The findings might be explained by the differences in the experimental models and the curvature and morphology of the root canal. From there constructed images of micro-CT after $\mathrm{Ca}(\mathrm{OH})_{2}$ removal, the residual easily appeared in the apical one-third, isthmus and irregular regions. Because of the complicated anatomy of the human root canal system, residual $\mathrm{Ca}$ $(\mathrm{OH})_{2}$ frequently remained in these regions. ${ }^{16,24,27-28}$ Because the effectiveness of irrigation could depend on both the mechanical flashing action and the chemical ability to dissolve tissue, ${ }^{29}$ it may be a good choice to apply the mechanical flushing action in combination with the decalcifying solution to remove $\mathrm{Ca}(\mathrm{OH})_{2}$ in the various root canals.
There were two aspects important for choosing instruments to remove $\mathrm{Ca}(\mathrm{OH})_{2}$. First, the instruments should enhance the agitation or shearing stress of irrigants in the root canal wall, such as passive ultrasonic irrigation, EndoActivator and EndoVac. ${ }^{16,25,28,30}$ The second aspect is mechanical removal realized by using instruments that fully contact the root canal wall. ${ }^{14,30-31}$ Moreover, some researchers have used both mechanical removal and irrigant agitation to enhance the effects of removal. ${ }^{17,32}$

Determining the most appropriate and effective method for removing $\mathrm{Ca}(\mathrm{OH})_{2}$ is important. The removal procedure has the potential to alter canal wall morphology. The decalcifying solution has the ability to demineralize dentin, and it takes more than $60 \mathrm{~s}$ to establish a trend of saturation. ${ }^{16,26}$ For EDTA, if given sufficient time to soften, a $50-\mu \mathrm{m}$ depth is capable of decalcifying dentin. ${ }^{29}$ Thus, the canal diameter would increase by $0.1 \mathrm{~mm}$. With a final rinse of $\mathrm{NaOCl}$ after the decalcifying solution, dentin erosion increases. ${ }^{29}$ The mechanical removal of $\mathrm{Ca}(\mathrm{OH})_{2}$ with root canal preparation instruments may affect the shape of the prepared root canal. $^{21}$ Recently, a study showed that the file-to-wall contact during ultrasonic activation of the irrigant occurred in all case studies. ${ }^{33}$ Therefore, the ultrasonic technique also has the potential to alter canal morphology unpredictably during root canal irrigation when removing $\mathrm{Ca}(\mathrm{OH})_{2}$. An investigation demonstrated that mechanical root canal preparation could generate high forces, resulting in dentinal defects and even dentin fractures. ${ }^{34}$ It is still unknown whether the use of decalcifying solution and mechanical instruments to remove $\mathrm{Ca}(\mathrm{OH})_{2}$ could increase the risk of dentinal defects, dentin fracture or root fracture. However, theoretically, the weak dentin wall could be a contributing factor to dentin fracture and root fracture. To prevent this scenario, some details must be highlighted, such as controlling the exposure time in decalcifying solution, using irrigants at the proper concentrations and sequence, and choosing instruments that are more gentle on the canal wall.

From previous studies, we found that many factors could affect the removal efficacy of $\mathrm{Ca}(\mathrm{OH})_{2}$, including the position of the syringe needle; ${ }^{35}$ the type, dosage and proportion of irrigants; ${ }^{11,13}$ and the application of instruments. ${ }^{14,16-17,24,28}$ However, no recommended $\mathrm{Ca}(\mathrm{OH})_{2}$ removal protocol is available that could be referenced in clinical practice. Therefore, on the basis of the conclusions of this study and the methods recommended in previous studies, a $\mathrm{Ca}(\mathrm{OH})_{2}$ removal protocol for curved root canals was proposed (Figure 6). Considering the various factors affecting calcium hydroxide removal, this system is a stable and effective method to remove $\mathrm{Ca}(\mathrm{OH})_{2}$ from the root canal system. This protocol uses more than $10 \mathrm{~mL}$ of irrigant. According to the clinical situation, the dosage of flushing fluid and times for instrument usage should be increased.

\section{CONCLUSION}

In this study, $\mathrm{Ca}(\mathrm{OH})_{2}$ could not be completely removed in most of the experimental groups. The decalcifying solution with the EndoActivator or passive ultrasonic irrigation effectively removes residual $\mathrm{Ca}$ $(\mathrm{OH})_{2}$ in a curved root canal system. An appropriate and effective method for removing $\mathrm{Ca}(\mathrm{OH})_{2}$ is important, and our findings support our recommendation for such a procedure.

\section{ACKNOWLEDGEMENTS}

This study was supported by projects from the Sichuan Science and Technology Department (Grant No. 2013JY0164) and the National Nature Science Foundation of China (Grant No. 81670980). 
1 Provenzano JC, Rôças IN, Tavares LF et al. Short-chain fatty acids in infected root canals of teeth with apical periodontitis before and after treatment. J Endod 2015; 41 (6): 831-835.

2 Mohammadi Z, Dummer PM. Properties and applications of calcium hydroxide in endodontics and dental traumatology. Int Endod J 2011; 44 (8): 697-730.

3 Marinho AC, Polay AR, Gomes BP. Accuracy of turbidimetric limulus amebocyte lysate assay for the recovery of endotoxin interacted with commonly used antimicrobial agents of endodontic therapy. J Endod 2015; 41 (10): 1653-1659.

4 Tavares WL, de Brito LC, Henriques LC et al. Effects of calcium hydroxide on cytokine expression in endodontic infections. J Endod 2012; 38 (10): 1368-1371.

5 Pereira MS, Rossi MA, Cardoso CR et al. Cellular and molecular tissue response to triple antibiotic intracanal dressing. J Endod 2014; 40 (4): 499-504.

6 Simcock RM, Hicks ML. Delivery of calcium hydroxide: comparison of four filling techniques. J Endod 2006; 32 (7): 680-682.

7 Kim SK, Kim YO. Influence of calcium hydroxide intracanal medication on apical seal. Int Endod J 2002; 35 (7): 623-628.

8 Calt S, Serper A. Dentinal tubule penetration of root canal sealers after root canal dressing with calcium hydroxide. J Endod 1999; 25 (6): 431-433.

9 Margelos J, Eliades G, Verdelis C et al. Interaction of calcium hydroxide with zinc oxideeugenol type sealers: a potential clinical problem. J Endod 1997; 23 (1): 43-48.

10 Erdemir A, Hale Ari, Güngüneş $\mathrm{H}$ et al. Effect of medications for root canal treatment on bonding to root canal dentin. J Endod 2004; 30 (2): 113-116.

11 Zorzin J, Wießner J, Wießner T et al. Removal of radioactively marked calcium hydroxide from the root canal: influence of volume of irrigation and activation. J Endod 2016; 42 (4): 637-640.

12 Rödig T, Vogel S, Zapf A et al. Efficacy of different irrigants in the removal of calcium hydroxide from root canals. Int Endod J 2010; 43 (6): 519-527.

13 Sağsen $B$, Ustün $Y$, Aslan $T$ et al. The effect of peracetic acid on removing calcium hydroxide from the root canals. J Endod 2012; 38 (9): 1197-1201.

14 Capar ID, Ozcan E, Arslan $\mathrm{H}$ et al. Effect of different final irrigation methods on the removal of calcium hydroxide from an artificial standardized groove in the apical third of root canals. J Endod 2014; 40 (3): 451-454.

15 Kuştarcı A, Er K, Siso SH et al. Efficacy of laser-activated irrigants in calcium hydroxide removal from the artificial grooves in root canals: an ex vivo study. Photomed Laser Surg 2016; 34 (5): 205-210.

16 Wigler R, Dvir R, Weisman A et al. Efficacy of XP-endo finisher files in the removal of calcium hydroxide paste from artificial standardized grooves in the apical third of oval root canals. Int Endod J 2016; doi:10.1111/iej.12668 (Epub ahead of print).

17 Wiseman A, Cox TC, Paranjpe A et al. Efficacy of sonic and ultrasonic activation for removal of calcium hydroxide from mesial canals of mandibular molars: a microtomographic study. J Endod 2011; 37 (2): 235-238.

18 De-Deus G. Research that matters-root canal filling and leakage studies. Int Endod J 2012; 45 (12): 1063-1064.

19 Schäfer E, Erler M, Dammaschke T. Comparative study on the shaping ability and cleaning efficiency of rotary Mtwo instruments. Part 2. Cleaning effectiveness and shaping ability in severely curved root canals of extracted teeth. Int Endod J 2006; 39 (3): 203-212.

20 Townsend C, Maki J. An in vitro comparison of new irrigation and agitation techniques to ultrasonic agitation in removing bacteria from a simulated root canal. J Endod 2009; 35 (7): 1040-1043.
21 Schneider SW. A comparison of canal preparations in straight and curved root canals. Oral Surg Oral Med Oral Pathol 1971; 32 (2): 271-275.

22 Gao Y, Haapasalo M, Shen Y et al. Development and validation of a three-dimensional computational fluid dynamics model of root canal irrigation. J Endod 2009; 35 (9): 1282-1287.

23 Elsherief SM, Zayet MK, Hamouda IM. Cone-beam computed tomography analysis of curved root canals after mechanical preparation with three nickel-titanium rotary instruments. J Biomed Res 2013; 27 (4): 326-335.

$24 \mathrm{Ma} \mathrm{JZ}$, Shen Y, Al-Ashaw AJ et al. Micro-computed tomography evaluation of the removal of calcium hydroxide medicament from $\mathrm{C}$-shaped root canals of mandibular second molars. Int Endod J 2015; 48 (4): 333-341.

25 Goode N, Khan S, Eid AA et al. Wall shear stress effects of different endodontic irrigation techniques and systems. J Dent 2013; 41 (7): 636-641.

26 Ballal NV, Kumar SR, Laxmikanth HK et al. Comparative evaluation of different chelators in removal of calcium hydroxide preparations from root canals. Aust Dent $J$ 2012; 57 (3): 344-348.

27 Rödig T, Hirschleb M, Zapf A et al. Comparison of ultrasonic irrigation and RinsEndo for the removal of calcium hydroxide and Ledermix paste from root canals. Int Endod $J$ 2011; 44 (12): 1155-1161.

28 Alturaiki $\mathrm{S}$, Lamphon $\mathrm{H}$, Edrees $\mathrm{H}$ et al. Efficacy of 3 different irrigation systems on removal of calcium hydroxide from the root canal: a scanning electron microscopic study. J Endod 2015; 41 (1): 97-101.

29 Basrani B, Haapasalo M. Update on endodontic irrigating solutions. Endod Topics 2012; 27 (1): 74-102.

30 Ethem Yaylali I, Kececi AD, Ureyen Kaya B. Ultrasonically activated irrigation to remove calcium hydroxide from apical third of human root canal system: a systematic review of in vitro studies. J Endod 2015; 41 (10): 1589-1599.

$31 \mathrm{Ma} J \mathrm{Z}$, Shen $\mathrm{Y}$, Yang $\mathrm{Y}$ et al. In vitro study of calcium hydroxide removal from mandibular molar root canals. J Endod 2015; 41 (4): 553-558.

32 Topçuoğlu HS, Düzgün S, Ceyhanlı KT et al. Efficacy of different irrigation techniques in the removal of calcium hydroxide from a simulated internal root resorption cavity. Int Endod J 2015; 48 (4): 309-316.

33 Boutsioukis C, Verhaagen B, Walmsley AD et al. Measurement and visualization of fileto-wall contact during ultrasonically activated irrigation in simulated canals. Int Endod J 2013; 46 (11): 1046-1055.

34 Hülsmann $M$. Effects of mechanical instrumentation and chemical irrigation on the root canal dentin and surrounding tissues. Endod Topics 2013; 29 (1): 55-86.

35 Chou K, George R, Walsh LJ. Effectiveness of different intracanal irrigation techniques in removing intracanal paste medicaments. Aust Endod J 2014; 40 (1): 21-25.

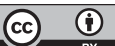

This work is licensed under a Creative Commons Attribution 4.0 International License. The images or other third party material in this article are included in the article's Creative Commons license, unless indicated otherwise in the credit line; if the material is not included under the Creative Commons license, users will need to obtain permission from the license holder to reproduce the material. To view a copy of this license, visit http://creativecommons.org/licenses/by/4.0/

(C) The Author(s) 2017 